The evolution of income-related inequalities in health care utilization in Switzerland over time

Robert E. Leu

Martin Schellhorn

04-13

September 2004

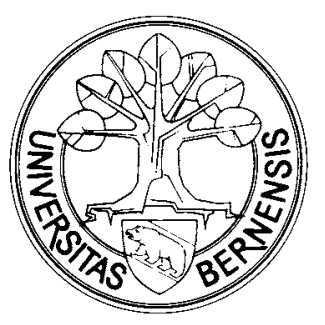

Universität Bern

Volkswirtschaftliches Institut

Gesellschaftstrasse 49

3012 Bern, Switzerland

Tel: 41 (0)31 6314506

Web: www.vwi.unibe.ch 


\title{
The evolution of income-related inequalities in health care utilization in Switzerland over time ${ }^{\dagger}$
}

\author{
Robert E. Leu, Department of Economics, University of Bern \\ Martin Schellhorn*, Institute for the Study of Labor IZA
}

\begin{abstract}
:
This study investigates equity in access to health care in Switzerland over time, using nationwide representative survey data from 1982, 1992, 1997 and 2002. Both simple quintile distributions and concentration indices are used to assess horizontal equity, i.e. the extent to which adults in equal need for medical care appear to have equal rates of medical care utilization. Looking at each of the four survey years separately the results indicate that by and large, there is little or no inequity in use except with respect to specialist visits which are clearly pro rich distributed as in most other OECD countries. We neither find much significant variation over time despite the fact that the share of health care has grown from close to $8 \%$ to more than $11 \%$ over this period and that a major reform of the health care system has taken place in 1996.
\end{abstract}

Key words: health care utilization, inequality

JEL codes: D32, I10, I12

\footnotetext{
${ }^{\dagger}$ The authors gratefully acknowledge partial funding through the National Research Program 45 "Future Problems of the Welfare State" of the Swiss National Science Foundation and collaboration with the members of the ECuity III project.

${ }^{*}$ Corresponding author; address: Institute for the Study of Labor, Schaumburg-Lippe-Str. 1, D- 53113 Bonn, Email: schellhorn@iza.org
} 


\section{Introduction}

Economists traditionally focus on efficiency. However, political decisions are notoriously cast by distributional considerations. This is most notably the case for social policy in general and health policy in particular. In the latter area the egalitarian view predominates that access to health care is every citizen's right (Williams 1993). This is reflected by the fact that a key policy objective in all OECD countries is to achieve adequate access to health care by all citizens on the basis of need. In line with the other OECD countries this egalitarian view predominates in Switzerland as well, at least as far as treatment aspects and not just amenities such as a (semi-)private hospital room are concerned. The overwhelming concern in the political debate seems to be that a two-class society with respect to health care should be avoided at all cost. This attitude is mirrored in the major reform of the Federal Health Insurance Law (KVG) enacted in 1996 which increased insurance coverage to $100 \%$, extended comprehensiveness of the compulsory basic insurance package and increased solidarity between the healthy and the sick, the rich and the poor and men and women. Equal access was an explicit goal of this reform.

This study investigates whether and to what extent these ideologies are reflected in actual utilization patterns. While the focus of our earlier research was on cross-country comparisons (see for example Van Doorslaer et al. 2000) we analyze in this paper the evolution of horizontal equity in health care utilization over time, using nationally representative survey data from 1982, 1992, 1997 and 2002. In the literature horizontal equity is usually interpreted to require that people in equal need of care are treated equally, irrespective of individual characteristics such as income, place of residence, race, etc. It is this principle of horizontal equity that the present study uses as the yardstick for the comparison over time as well. The method we employ to describe and measure the degree of horizontal inequity in health care delivery is conceptually identical to the one used in Wagstaff and van Doorslaer (2000b), van Doorslaer et al. (2000), van Doorslaer et al. (2004) and van Doorslaer and Koolman (2004a) for cross-country comparisons. The method proceeds by comparing the actual observed distribution of medical care by income with the distribution of need. The results can be interpreted readily as performance measure of the Swiss health care system with respect to equity.

The paper is organized as follows: Section 2 provides a rather comprehensive description of the major features of the Swiss health care system as it emerged after the 
1996 reform, including the relevant changes relative to the legislation preceding the reform. Section 3 outlines the estimation methods used. Data and variable definitions are discussed in section 4 while the results are displayed in section 5 . Section 6 concludes.

\section{The Swiss health care system}

The Swiss health care system, instituted 1911 and revised 1996, is characterized by the following features:

a) All permanent residents have to buy a compulsory basic health insurance policy from one of the officially acknowledged health insurance companies. Compulsory insurance policies can be freely changed by the end of each year. In addition, there is the possibility to buy supplementary health insurance (see below).

b) There is a wide variety of compulsory policies. In the traditional fee-for-service sector which still accounts for over $90 \%$ of all insurance contracts policies may be differentiated by deductible levels. By contrast, there is no deductible for HMO plans which closely manage access to providers. A further possibility is to choose a "bonus" plan, a five-year policy that rewards enrollees who do not use insurance with substantial reductions in premiums.

c) Compulsory insurance policies cover outpatient care, including a wide variety of providers, hospital care $(100 \%$ coverage on the general ward of a public or publicly subsidized hospital in the enrollees' canton, except for a co-payment of CHF 10 per day), prescription drugs listed, preventive vaccinations, prescribed treatments in health resorts and alternative medicine. In addition, there are contributions to certain preventive tests, home care, glasses and medical devices as well as transportation and salvage expenses. In emergency cases up to twice the rate of the cantonal tariffs are paid for treatments abroad. Dental care, by contrast, is only covered in case of accident or severe dental problems. Compulsory insurance in the fee-for-service sector offers direct access and free choice of physician for outpatient care (general practitioners and specialists). Except for emergency cases hospitalisation requires referral by a physician. There is no choice of physician in the hospital. However, patients may freely choose among all hospitals which are included on the cantonal eligibility list. 
d) Supplementary insurance covers additional treatments and check-ups, all drugs, extended home care, provides generally higher benefits and up to $100 \%$ universal coverage world wide. Most important it provides access to the private ward of all public and private hospitals in a one or two-bedroom and free choice of physician in the hospital (medical or assistant medical director), depending on insurance package.

e) The overall number of insurance companies has decreased massively over the last decades, from 1'100 in 1960 to 93 in 2003. Since not all of these companies were active in all cantons consumers could choose from between 51 to 72 companies in each canton. Some of these companies have existed for more than 100 years, others are relatively new. Some have less than five thousand enrollees, others more than one million. There is free competition among the health insurance companies within the boundaries set by the Federal Health Insurance Law.

f) Insurance companies offering compulsory insurance policies are heavily regulated. They may not be profit-oriented, have to offer the same basic insurance package, and premiums as well as benefits are tightly controlled by the federal government. While insurers can reject supplementary insurance applicants, they must accept all those who apply for compulsory insurance. Premiums for compulsory insurance policies may only be differentiated by canton, type of region (urban, rural or suburban) and age (reduced premiums for children and young adults). To reduce the amount of risk selection induced by this type of premium regulation all insurance companies have to participate in a risk-adjustment pool. Depending on the risk structure of their enrollees insurers pay or receive contributions from this pool. Supplementary insurance policies may, by contrast, be adjusted for the enrollees' risk, and insurers may be for-profit.

g) The Swiss health care system is financed out of four sources, compulsory health and casualty insurance $(31.9 \%$ in 2001$)$, supplementary health insurance $(10.2 \%)$, out-ofpocket payments (including dental care) and donations (32.7\%) and taxes (25.2\%). Roughly $58 \%$ of the tax revenues were provided by the cantons, $31 \%$ by the communities and $11 \%$ by the federal government. As mentioned above, health insurance premiums do not depend on income. To ease the financial hardship associated with per capita premiums, government provides means - tested subsidies to low income residents. In 2001 roughly one third of the insured were subsidized to 
some extent, and about $15 \%$ of all enrollee premium payments were paid for by the government. Subsidies are paid if premiums exceed a certain percentage of household income - usually $8 \%-10 \%$. The maximum amount paid is typically the mean of the premiums of all insurance companies in the canton. Essentially, this means that the poor get free care. In the fee-for-service sector patients have to pay a deductible of their choice (within a range set by the government) and a coinsurance rate of $10 \%$. This explains the relatively high share of out-of-pocket payments. Insuring compulsory out-of-pocket payments is not permitted. Premium reductions associated with higher deductibles are regulated by government as well.

h) Licensed physicians are free to choose their location for outpatient care. Government is restricted to control the formal educational requirements for licensing. Physicians' fees for compulsory policies in the fee-for-service sector are negotiated between their union and the Swiss insurance association on the cantonal level and are overviewed by the government. If a consensus cannot be reached fees are set by the cantonal governments. By contrast, fees are not regulated with respect to supplementary insurance. Hence anti-trust law applies. Physicians can bill only for services that are covered by the insurer and may not supplement their bills for compulsory enrollees. In the fee-for-service sector every licensed physician can bill every compulsory insurance policy (enforced contracting), i.e. the insurer cannot choose preferred providers except in the context of managed care, while providers cannot refuse treatment to any patient with a compulsory insurance policy.

i) In 1999 there were 249 public or publicly subsidized and 143 private hospitals in Switzerland. The former accounted for roughly $80 \%$ of total acute care bed capacity. Public and publicly-subsidized hospitals are operated by the cantons or the communities in which they are located or by some other non-profit organization. They are guaranteed deficit coverage and/or subsidies from public funds. Capital investments, education, research expenses and at least $50 \%$ of the operating costs are financed by cantonal tax revenues. Since 1996, cantons can impose fixed budgets on public or publicly-subsidized hospitals. Private hospitals which may be organized as for-profit or non-profit are not eligible for public funds and have to substitute tax subsidies by payments from supplementary health insurance and patients. Prices (tariffs) for public hospitals are negotiated between the hospital association, the insurers association and the government on the cantonal level. Private hospitals 
negotiate their own fees with the insurers and may not agree on a universal tariff because of the anti-trust law. Insurance companies usually pay hospitals per diem fees. In a number of cantons APDRGs (all patient diagnosis-related groups) have been introduced to pay public hospitals a flat rate per patient. The higher per diem rates for "hotel" costs and services in the private ward are covered by supplementary health insurance or out-of-pocket payments.

j) Although the Swiss health care system is basically consumer-driven, government plays an important role. The system mirrors the federal structure of the country in that the cantons are responsible for securing the provision of health care according to the constitution. The health insurance law on the federal level provides the basic guidelines within which the cantons, the communities and the various other players can operate. In addition, the federal government participates in the financing of the means-tested premium subsidies operated by the cantons. The bulk of the tax revenues flowing into the health sector stems from the cantons, however. They are the dominant player in the hospital sector. Together with the communities they own and operate a majority of hospitals, finance more than $50 \%$ of hospital costs, participate in the negotiation of fees and tariffs, and set the tariffs if negotiations are not successful. Last but not least they set up the eligibility list which is crucial for the remuneration of hospitals. Listed hospitals are entitled to tax subsidies and can bill every compulsory insurance policy for all services included in the basic package. Since the cantons control together with the communities on average about $80 \%$ of total bed capacity their position in the provision of inpatient care is very powerful, determining the allocation of hospital resources to a large extent.

k) In comparison with other highly developed countries like Germany, Great Britain, Canada or even the US the population in Switzerland generally has more health care resources available (OECD 2002). While this may be seen as an achievement - the share of GNP for health care amounts to roughly $11 \%$ - economists have argued that the level of provision is in some areas inefficiently high, in particular with respect to hospital care. The positive side of this ample capacity is that queuing is not a major problem and that shortages of care in rural areas do not occur to any significant degree despite large differences in regional health care supply. Quality of care is generally regarded as high and health outcomes measured by selected indicators compare favourably with those of other countries (WHO 2000, OECD 2002). $24 \%$ of 
the population rate their health status as very good, $62 \%$ as good, $11 \%$ as average and $3 \%$ as poor or very poor (Swiss Health Survey 2002).

Most of the institutional features described above have been brought about by the 1996 reform of the Health Insurance Law. Three main goals were pursued with this major reform: a) Extension of the insurance coverage for the entire population (universal coverage, expansion of the compulsory basic insurance package); b) increase in solidarity between the healthy and the sick, the rich an the poor and men and women (flat insurance premiums, premium subsidies and universal access to compulsory health insurance); c) reduction in cost inflation. There is widespread agreement that the first two goals have been achieved to a considerable degree, while cost inflation remains a major problem. Extended insurance coverage and increased solidarity can be expected to have increased equity in utilization. In addition, supplementary insurance coverage which is known to contribute to inequities in use has decreased since 1996 due to the extension of the compulsory insurance package. By contrast, the instruments of the revised law aiming at reducing costs, in particular increased cost-sharing and managed care options tend to reduce equity. Since neither explicit rationing nor sizable queues have been observed so far we do not expect, on the other hand, that the possibility of imposing a fixed budget on public hospitals has influenced the distribution of health care. Overall, we are left without a clear a priori hypothesis of whether the 1996 reform has increased or decreased equity in utilization. Tackling this question therefore boils down to a purely empirical exercise, using nationwide representative survey data before and after 1996 and keeping in mind that other factors may have exerted an influence over this extended period of time as well.

\section{Estimation methods}

This section draws heavily on the OECD Health Working Paper No. 14 by van Doorslaer et al. (2004) to which the authors have contributed as members of the OECD Health Equity Research Group. Health care utilisation data like physician visits are known to have skewed distributions with typically a large majority of survey respondents reporting zero or very few visits and only a very small proportion reporting frequent use. Because these features cause violations of the standard OLS model, various specifications of intrinsically non-linear two-part models (TPM) have been proposed in the literature, distinguishing between the probability of positive usage and the conditional amount of 
usage given positive use in the reference period (see Jones, 2000, for a review). While these models have certain advantages over OLS specifications, their intrinsic nonlinearity makes the (linear) decomposition method described in section 3.2 impossible. In order to restore the mechanics of the decomposition, one has to revert to either decomposing inequality in the (latent variable) propensity to use (rather than actual use) or to a re-linearization of the models using approximations (see Van Doorslaer, Koolman and Jones, 2003, for an example). However, Van Doorslaer et al. (2000) have shown that the measurement of horizontal inequity hardly differs between OLS-based TPMs and non-linear TPM specifications such as the logistic model combined with a truncated negative binomial model.

Following the OECD paper, we have therefore chosen a pragmatic approach. We use simple OLS estimation for the decomposition based measures and we check the sensitivity of the $\mathrm{HI}$ indices and quintile distributions by comparing these with the indices and distributions obtained using non-linear specifications. We obtained "needed" health care use based on a generalized negative binomial model for total consumption, a logistic specification for the probability of use, and a truncated negative binomial model for the conditional positive use. In comparing the $\mathrm{HI}$ indices obtained using linear versus nonlinear models, we found that the estimates are extremely similar and that in only very few cases, the linearly and non-linearly estimated indices differ significantly (not shown). This provides some reassurance that our results are not conditional on the choice of the linear standardization model.

For the four survey years, cross-sectional sample weights were used in all computations in order to make the results more representative of Switzerland's population. Robust standard errors were obtained using the Huber/White/Sandwich estimator.

\subsection{Measuring inequity}

This study measures distributions of actual and needed use of care by income quintiles. These are groups of equal size, each representing 20\% of the total (adult) population, but ranked by their household income from poorest to richest. The "needed" health care use is computed by running a regression on all individuals in the sample, 
explaining medical care use (e.g. doctor visits or hospital nights) with a set of explanatory variables. This means running a linear OLS regression equation like

$$
\text { [1] } \quad y_{i}=\alpha+\beta \ln i n c_{i}+\sum_{k} \gamma_{k} x_{k, i}+\sum_{p} \delta_{p} z_{p, i}+\varepsilon_{i}
$$

where $y_{i}$ denotes the dependent variable (medical care use of individual $i$ in a given period). We distinguish between three types of explanatory variables: the (logarithm of) the household income of individual $i\left(\ln i n c_{i}\right)$, a set of $k$ need indicator variables $\left(x_{k}\right)$ including demographic and morbidity variables, and $p$ other, non-need variables $\left(z_{p}\right) . \alpha$, $\beta, \gamma_{k}$ and $\delta_{p}$ are parameters and $\varepsilon_{i}$ is an error term.

Equation 1 can be used to generate need-predicted values of $y$, i.e. the expected use of medical care of individual $i$ on the basis of his/her need characteristics. It indicates the amount of medical care $\mathrm{s} / \mathrm{he}$ would have received if $\mathrm{s} / \mathrm{he}$ had been treated as others with the same need characteristics, on average. Combining OLS estimates of the coefficients in Equation (1) with actual values of the $x_{k}$ variables and sample mean values of the $\ln i n c_{i}$ and $z_{p}$ variables, we can obtain the need-predicted, or "x-expected" values of utilisation, $\hat{y}_{i}^{X}$ as:

$$
\hat{y}_{i}^{X}=\hat{\alpha}+\hat{\beta} \ln i n c^{m}+\sum_{k} \hat{\gamma}_{k} x_{k, i}+\sum_{p} \hat{\delta}_{p} z_{p}^{m}
$$

Estimates of the (indirectly) need-standardized utilisation, $\hat{y}_{i}^{I S}$, are then obtained as the difference between actual and x-expected utilisation, plus the sample mean $\left(y^{m}\right)$

$$
\hat{y}_{i}^{I S}=y_{i}-\hat{y}_{i}^{X}+y^{m}
$$

The quintile means of these indirectly standardized values give our needstandardized distributions of medical care. They are to be interpreted as the distributions to be expected if need were equally distributed across quintiles.

But these quintile distributions are difficult to compare across a large number of several data points and types of care use. It is therefore useful to summarize the degree of inequality observed using a concentration index. It is defined as (twice) the area between a concentration curve and a line of perfect equality. A medical care concentration curve 
plots the cumulative proportion of medical care against the cumulative proportion $R$ of the sample, ranked by income (Wagstaff and Van Doorslaer, 2000a and b).

A concentration index of a variable $y$ can be computed using a simple "convenient covariance" formula, which looks as follows for weighted data:

$$
C=\frac{2}{y^{m}} \sum_{i=1}^{n} w_{i}\left(y_{i}-y^{m}\right)\left(R_{i}-R^{m}\right)=\frac{2}{\mu} \operatorname{cov}_{w}\left(y_{i}, R_{i}\right)
$$

where $y^{m}$ is the weighted sample mean of $y, \operatorname{cov}_{w}$ denotes the weighted covariance and $R_{i}$ is the (representatively positioned) relative fractional rank of the $i$ th individual, defined as :

$$
\text { [5] } \quad R_{i}=\frac{1}{n} \sum_{j=1}^{i-1} w_{j}+\frac{1}{2} w_{i}
$$

where $w_{i}$ denotes the sampling weight of the $i$ th individual and the sum of $w_{i}$ equals the sample size (n).

Testing for differences between concentration indices requires confidence intervals. Robust estimates for $\mathrm{C}$ and its standard error can be obtained by running the following convenient (weighted least squares) regression of (transformed) $y$ on relative rank:

$$
\text { [6] } \frac{2 \sigma_{R}^{2}}{y^{m}} y_{i}=\alpha_{1}+\beta_{1} R_{i}+\varepsilon_{1, i} \text {, }
$$

where $\sigma_{R}^{2}$ is the variance of $R_{i}$ and $\hat{\beta}_{1}$ is equal to $\mathrm{C}$, and the estimated standard error of $\hat{\beta}_{1}$ provides the estimated standard error of $\mathrm{C}$.

The concentration index of the actual medical care use measures the degree of inequality and the concentration index of the need-standardized use (which is our horizontal inequity index HI) measures the degree of horizontal inequity. When it equals zero, it indicates equality or equity. When it is positive, it indicates pro-rich inequality/inequity, and when it is negative, it indicates pro-poor inequality/inequity.

It is worth emphasizing that coinciding concentration curves for need and actual use provide a sufficient but not a necessary condition for no inequity. Even with crossing curves, one could have zero inequity if, for example, inequity favoring the poor in one part of the distribution exactly offsets inequity favoring the rich in another 


\subsection{Decomposing and explaining horizontal inequity}

It is possible to estimate the separate "contributions" of the various determinants and their relative importance. Using the regression coefficients $\gamma_{k}$, (partial) elasticities of medical care use with respect to each determinant $k$ can then be defined as:

[7] $\quad \eta_{k}=\gamma_{k} x_{k}^{m} / y^{m}$

where $y^{m}$ is the (population weighted mean) of $y$ and $x_{k}^{m}$ is the (population weighted) mean of $x_{k}$. These elasticities denote the percentage change in $y$ resulting from a percentage change in $x_{k}$.

It has been shown (Wagstaff, Van Doorslaer and Watanabe, 2003) that the total concentration index can then be written as:

[8] $\quad C=\eta_{r} C_{\ln i n c}+\sum_{k} \eta_{k} C_{x, k}+\sum_{p} \eta_{p} C_{z, p}+G C_{\varepsilon}$

where the first term denotes the partial contribution of income inequality, the second the (partial) contribution of the need variables, and the third the (partial) contribution of the other variables. The last term is the generalized concentration index of the error term $\varepsilon$.

In other words, estimated inequality in predicted medical care use is a weighted sum of the inequality in each of its determinants, with the weights equal to the medical care use elasticities of the determinants. The decomposition also makes clear how each determinant $k$ 's separate contribution to total income-related inequality in health care demand can be decomposed into two meaningful parts: i) its impact on use, as measured by the use elasticity $\left(\eta_{k}\right)$, and ii) its degree of unequal distribution across income, as measured by the (income) concentration index $\left(C_{k}\right)$. This decomposition method therefore not only allows us to separate the contributions of the various determinants, but also to identify the importance of each of these two components within each factor's total contribution. This property makes it a powerful tool for unpacking the mechanisms contributing to a country's degree of inequality and inequity in use of health care. 


\section{Data and variable definitions}

The data used in this paper were taken from four nationwide representative crosssectional data sets, the survey on Socio-Medical Indicators for the Population of Switzerland (SOMIPOPS) which was collected in 1982, and the Swiss Health Surveys (SHS) 1992, 1997 and 2002. While the latter three use almost identical questions, there are some notable differences between SOMIPOPS and the SHS data sets. First, while the information on household income in SOMIPOPS is derived from official tax records (see Leu et al. (1986)) income in the SHS data is self-reported. We cannot exclude that the substantial increase in income from 1982 to 1992 is at least partly due to this difference in data source. In the present context, this causes a problem only if the two income variables lead to a different ranking of individuals by income. Second, the self-assessed health question in SOMIPOPS has only four categories (very good, good, fair, bad) while the SAH questionnaire contains five items ranging from "very good" to "very bad". The other two health variables used are coded as dummy-variables. The first is derived from questions on the existence of twelve different physician-diagnosed but self-reported chronic illnesses which were included in all surveys. The second addresses problems with activities of daily life (ADL) and is derived from comparable questions on the existence on a physical or mental health problem which hampers individuals in daily life. One problem with the 1992 SHS data set is that it only contains information on all physician visits which cannot be disentangled into GP and specialist visits. Table 1 presents descriptive statistics for the four data sets.

\section{Results}

\subsection{The evolution over time}

In table 2 we show the distribution of need-standardized medical care use by income quintile for the various care categories, the utilization concentration index $C_{M}$ and the horizontal inequity index HI for each of the four years. Statistically significant concentration indices and horizontal inequity indices are printed in bold. The needstandardized distribution is the one which would be observed with equal need across the income groups. It is derived by equalizing need in the quintile groups by means of indirect standardization. Need is proxied by nine age-gender dummy variables, four dummy variables for the different SAH categories and two further dummy variables 
indicating the existence of a chronic condition or handicap which hampers the individual in its daily activities. Any inequality which remains after need-standardization is interpreted as inequitable. If utilization was equitable then utilization of the various care categories would be equal across income groups.

We further disentangle total use into the probability of accessing a specific care category at all and the conditional number of visits with a physician given an initial contact has taken place. The evolution of the HI indices for all physician visits, GP visits, specialist visits and hospital nights is also illustrated by figures 1a to $1 \mathrm{~d}$ which display the $\mathrm{HI}$ indices and their standard errors for all visits/hospital nights, the probability of a visit/hospital night and the conditional number of visits/hospital nights.

An interesting observation emerging from table 2 and figures $1 \mathrm{a}$ to $1 \mathrm{~d}$ is that the probability of a physician visit is in each of the four years more pro-rich distributed than the conditional number of visits. Arguing along the lines of a two-part model where the initial contact with a physician is the choice of the patient while subsequent consultations are decided upon by the physician this finding suggests that if inequity occurs it is driven by the behaviour and incentives of the patients and not by those of the physicians. However, with the exception of specialist visits which are distributed significantly prorich in each year and to an increasing extent over time, none of the utilization categories is systematically distributed inequitably and no clear time trend is observable for most categories as well.

Table 2 indicates that the average number of physician visits dropped from 4.6 in 1982 to 3.5 in 2002 . There appears to be a steady decline except for the year 1992 where the number of physician visits had been collected differently than in the other years. ${ }^{1}$ The horizontal inequity index remains close to zero and is statistically insignificant in all four years.

The reduction in total visits is mainly due to a reduction in primary care physician visits. The average number of these visits dropped from 3.2 in 1982 to 2.3 per year in 2002 while the average number of specialist visits remained almost unchanged at 1.5. Specialist visits tend to be increasingly pro-rich distributed with the $\mathrm{HI}$ index rising from

\footnotetext{
${ }^{1}$ In 1992 the total number of visits was calculated by adding up the number of visits caused by illness, check-ups and other preventive measures; in the three other years it was calculated by adding up primary physician and specialist visits.
} 
(insignificant) 0.022 to (significant) 0.071 . In 2002 the poorest quintile of the population saw a specialist on average 1.3 times per year (after standardization for need) while the richest quintile contacted a specialist 1.8 times per year. This pro-rich distribution mainly stems from a pro-rich distribution in the probability of consulting a specialist and not from an inequality in having (conditional) subsequent consultations. As the $\mathrm{HI}$ index for all physician visits is statistically insignificant, the pro-rich distribution of specialist visits is offset by a pro-poor albeit insignificant distribution of primary care physicians.

Except for 1992 where the HI index is significantly pro-poor the total number of hospital nights is equally distributed in the population. The average number of hospital nights decreased from 1.4 to 1.2 between 1982 and 2002. This decline occurred in the first decade of our observation period and results from a decline of the average length of a hospital spell from 14 days in 1982 to slightly below 10 days in subsequent years. This decline in the average length of a hospital spell is partially offset by an increased probability of experiencing a hospital stay which rises from 11 percent in 1982 to 13 percent in 2002. Except for 1982 the probability of having a hospital stay is pro-poor distributed.

As described in section 3.2 the separate contribution of the various determinants to total inequality can be estimated as well. This is accomplished in figures 2 to 5 , again for the total number of visits (hospital nights), the probability of at least one visit (hospital stay) and the conditional number of visits (hospital nights) for the four utilization categories. In these figures the contributions of several variables which have been used in the regressions are added up to form reasonable categories. Need encompasses the effects modelled by the SAH category dummies, the chronic condition dummy and the dummy for problems with ADL. Income reflects the direct effect of (log-)income, education adds up the effects of two dummies reflecting a higher educational attainment, age reflects the 10 age-gender dummies, activity status is formed from dummies reflecting the main activity of an individual (employed, self-employed, unemployed, retired, in education, housewife/-man, other reasons for being inactive) and region is formed from seven Swiss regions.

The decomposition graphs show that the most important determinant of higher health care utilization among the poorer individuals is the unequal distribution of health across the population. It should be mentioned, however, that Switzerland exhibits one of the 
most equal distributions of health, as can be seen by comparing results from a study on inequalities in health in Switzerland over time by Leu and Schellhorn (2004) with the international results from van Doorslaer and Koolman (2004a).

Interestingly, for all physician visits and for GP visits this unequal distribution of health contributes to total inequality in health care utilization mostly through conditional utilization and less through the probability of any use. By contrast, the non-need factors income and education play a more important role in the probability of consultations than in the conditional number of visits. Again, this seems to indicate that the two-part model is adequate for individual health care utilization. Non-need factors have relatively little impact on utilization once the patient is in the system but matter somewhat for the patient-driven decision to access care.

The non-need factors are particularly important for specialist visits. The increased inequity in all specialist visits is mostly explained by the difference in the direct effect of income on the conditional number of specialist visits which switches from slightly propoor in 1982 to strongly pro-rich in 2002. A similar time trend is observed for the direct effect of income on the conditional number of hospital nights.

Apart from this finding most of the factors show no clear time trend for their contribution to inequalities in health care utilization as is observable in figures 2 to 5 . An exception is again the direct effect of income on the probability of at least one physician visit which becomes less pro rich after 1992.

Another important non-need factor contributing to unequal utilization is activity status. There are two potentially valid explanations for this finding. First, activity status might be correlated with unobservable aspects of health, for example, an individual might be retired or inactive because of bad health. Second, activity status contains information about the opportunity cost of a visit or a hospital stay. For example a retired individual might have less severe time constraints than a full-time working individual. The former hypothesis is supported by the fact that activity status plays a role mainly through its impact on conditional visits rather than through the probability of a physician visit. In addition, the detailed decomposition analysis shows for all utilization categories that within the activity status variable retirement is the most important factor contributing to 
inequality. This indicates that retirement should probably be rather labelled as a needfactor.

The contributions of the various factors can be further decomposed into the partial utilization elasticities of a specific factor and the concentration of this factor in the population with regard to income. As an example table 3 provides this more detailed decomposition for the total number of specialist visits in 2002. We show, the means, the concentration indices with regard to income, the estimated coefficients from the interval regressions $(\mathrm{ME})$ and the contribution to total inequality of each factor. The omitted reference categories used in the estimations are a very good $\mathrm{SAH}$, being a male in the age group 18-34, having only mandatory education, working (full-time) for activity status, living in the cantons around Lake Geneva, and the minimal deductible for mandatory basic health insurance for the years 1997 (150 CHF per year) and 2002 (230 CHF per year).

The numbers indicate that most of the observed income-related inequality can be attributed to a direct effect of income on utilization. Log-income has a CI of 0.035 and a positive ME on utilization of 0.3. Average to very poor SAH states, the existence of chronic conditions or restrictions in ADL are concentrated among the poorer individuals (negative CI) and have a positive effect on the number of visits (a positive ME), thereby leading to a pro-poor shift in the distribution of this utilization category. Higher educational attainment is concentrated among the richer individuals and exerts a positive ME on specialist visits. Another variable which is concentrated among the richer individuals and has a positive ME is the existence of supplementary insurance. On the other hand, the choice of deductible which was introduced with the 1996 health system reform has a pro-poor impact on the total number of specialist visits. The higher deductibles are chosen by richer individuals and have a negative ME on the number of visits. Whether this negative ME indicates incentive effects or reflects unobserved aspects of health is a much debated issue in the literature (see e.g. Schellhorn 2001, 2002a,b and Werblow and Felder 2003) and subject of ongoing research. There is also substantial inequality in utilization across regions. The varying ME of the various regions on utilization can be partly explained by the different specialist densities across these regions. 


\subsection{The Swiss results in the international context}

To put the Swiss results into a meaningful context we compare them with the results of recently published studies by van Doorslaer et al. (2004) and van Doorslaer and Koolman (2004b) which compares income-related inequality in health care utilization across 21 OECD countries and 12 EU countries respectively. With respect to all physician visits there are no significant inequities (controlling for need) in a majority of these countries including Switzerland. The distribution is pro-poor in Ireland and Belgium, and pro-rich in the US, Finland, Sweden and Austria. In about half of these countries the distribution is pro-poor for GP visits. In Finland, it is pro-rich while no significant differences can be found in the remaining countries including Switzerland. The situation is very different for specialist visits. In every country for which the necessary data exist the rich are more likely to see a specialist, after controlling for need differences, and in most countries the rich visit a specialist also more frequently. The HIIndex for Switzerland takes a midfield position in the group of countries showing prorich inequity. Finally, no significant inequities can be found with respect to hospital nights in the 21 countries excepting Canada (pro-poor) and Mexico (pro-rich). The HI index for Switzerland is among the most pro-poor.

\section{Conclusions}

We have used both simple quintile distributions and concentration indices estimated using regression models to assess the extent to which adults in equal need for medical care appear to have equal rates of medical care utilization in Switzerland. In particular, we have focused on the evolution of horizontal equity in health care utilization over the last two decades, using nationally representative survey data for 1982, 1992, 1997 and 2002. We believe that this approach is justified because the horizontal equity principle "equal treatment for equal need" is a widely accepted policy goal in Switzerland as far as compulsory health insurance is concerned.

Except for specialist visits (and hospital nights in 1982) we have found no significant differences in the distribution of medical care by income. For all those who share the egalitarian interpretation of horizontal equity this is good news. However, a crucial question which cannot be tackled with survey data is whether and to what extent the remaining differences translate into inequities in health outcomes. A related question is 
whether treatment quality is the same even when there are no inequities in utilization, measured by physician visits and hospital days. For example, it might be that the better off (the better educated) get their treatment in better hospitals or are treated by better qualified physicians once they experience a hospital spell (in particular, when they have supplementary insurance). The described inequity in accessing specialists might have such an effect as well.

In line with the international literature we find that the most important contributor to income-related inequalities in health care utilization is an unequal distribution of need. The most important contributors to inequities are the direct effect of income on utilization, the effect of educational attainment and retirement status. Again, this replicates the international findings.

Our analysis shows that the values of the computed inequity indices, albeit insignificant in most cases, vary considerably and unsystematically over time. If the same is true in other countries it obviously matters which year is chosen for cross-country comparisons. Even if the changes of these indices are insignificant when one looks at the evolution over time in one country they might well be relevant in international comparisons with respect to the statistical significance of differences in the HI indices.

Looking at the evolution of the equity indices over time we find little significant differences. There appears to be a decreasing inequity in the probability of seeing a physician at all and a trend towards pro-rich inequity in the conditional number of specialist visits as well as of hospital nights. The utilization data thus do not reveal any systematic influence of the 1996 health care reform. It is possible, however, that the various elements of the reform have just about neutralized each other. There are indeed some indications for this possibility. For example, the contribution of supplementary insurance to the probability of seeing a specialist or having a hospital spell decreases over time. This is in line with the observation that the incidence of supplementary insurance contracts decreased strongly between 1996 and 2002 because of the reform. 


\section{References}

Jones, A.M. (2000), "Health Econometrics", in A.J. Culyer and J.P. Newhouse (eds.), Handbook of Health Economics, Elsevier, 265-344.

Leu, R., B. Buhmann and R.L. Frey (1986): "Die personelle Einkommens- und Vermögensverteilung der Schweiz 1982", Swiss Journal of Economics and Statistics 22: 111-142.

Leu, R.E. und M. Schellhorn (2004): "The evolution of income-related inequalities in health in Switzerland over time", Diskussionsschriften des Departements für Volkswirtschaftslehre der Universität Bern, Nr. 04.14

OECD 2002, OECD Health Data, Paris.

Schellhorn, M. (2001): "The Effect of Variable Health Insurance Deductibles on the Demand for Physician Visits", Health Economics 10: 441-456.

Schellhorn, M (2002a): "A comparison of alternative methods to model endogeneity in count models. An application to the demand for health care and health insurance choice", mimeo, IZA Bonn.

Schellhorn, M (2002b): The Demand for Health Care. Swiss Evidence, Berlin, dissertation.de.

Van Doorslaer, E. and X. Koolman (2004a), "Explaining Income-related Health Inequalities across European Countries", Health Economics 13(7): 609-628.

Van Doorslaer, E. and X. Koolman (2004b), "Explaining Income-related Inequalities in Doctor Utilisation in Europe", Health Economics 13(7): 629-648

Van Doorslaer, E., Wagstaff, A., van der Burg, H., Christiansen, T., De Graeve, D., Duchesne, I., Gerdtham, U-G, Gerfin, M., Geurts, J., Gross, L., Häkkinen, U., John, J., Klavus, J., Leu, R.E., Nolan, B., O’Donnell, O., Propper, C., Puffer, F., Schellhorn, M., Sundberg, G. and Winkelhake, O. (2000), "Equity in the Delivery of Health Care in Europe and the US", Journal of Health Economics, 19(5): 553583.

Van Doorslaer, E., C. Masseria and the OECD Health Equity Research Group (2004): Income-related inequalities in the use of medical care in 21 OECD countries, OECD Health Working Paper No. 14. Reprinted in: The OECD Health Project. Towards High-Performance Health Systems: Policy Studies, Geneva, chapter 3: 109-165; also: OECD Health Working Paper No.14.

Wagstaff, A. and E. van Doorslaer, (2000a), "Measuring and Testing for Inequity in the Delivery of Health Care", Journal of Human Resources 35(4): 716-733.

Wagstaff, A. and E. van Doorslaer (2000b), "Equity in Health Care Financing and Delivery", in A.J. Culyer and J.P. Newhouse (eds.), Handbook of Health Economics, North Holland, 1803-1862. 
Wagstaff, A., E. van Doorslaer and N. Watanabe (2003), "On Decomposing Health Sector Inequalities, with an Application to Malnutrition Inequalities in Vietnam", Journal of Econometrics, 112(1): 207-223.

Werblow, A. and S. Felder (2003): "Der Einfluss von freiwilligen Selbstbehalten in der Gesetzlichen Krankenversicherung. Evidenz aus der Schweiz“, Schmollers Jahrbuch 123: 235-264.

WHO (2000): The World Health Report 2000, Geneva.

Williams, A.H. (1993): "Equity in health care: the role of ideology", in: Van Doorslaer, E., A. Wagstaff and F. Rutten (eds.), Equity in the finance and delivey of health care: an international perspective, Oxford University Press, Oxford, 287-298. 
Table 1: Descriptive statistics

\begin{tabular}{l|cccc} 
& $\mathbf{1 9 8 2}$ & $\mathbf{1 9 9 2}$ & $\mathbf{1 9 9 7}$ & $\mathbf{2 0 0 2}$ \\
\hline $\mathrm{N}$ & 3981 & 9764 & 9827 & 13692 \\
All visits & 4.60 & 3.32 & 3.78 & 3.34 \\
GP visits & 3.23 & - & 2.37 & 2.14 \\
Specialist visits & 1.37 & - & 1.41 & 1.45 \\
Hospital nights & 1.42 & 1.07 & 1.15 & 1.10 \\
SAH very good & 0.23 & 0.28 & 0.27 & 0.23 \\
SAH good & 0.63 & 0.57 & 0.58 & 0.62 \\
SAH average/fair & 0.12 & 0.12 & 0.12 & 0.11 \\
SAH poor & 0.01 & 0.03 & 0.03 & 0.03 \\
SAH very poor & & 0.01 & 0.00 & 0.00 \\
Chronic condition & 0.39 & 0.29 & 0.30 & 0.25 \\
ADL & 0.05 & 0.12 & 0.16 & 0.17 \\
Ininc & 7.42 & 7.94 & 8.12 & 7.96 \\
Male 35-45 & 0.21 & 0.10 & 0.11 & 0.12 \\
Male 45-64 & 0.13 & 0.15 & 0.16 & 0.18 \\
Male 65-74 & 0.06 & 0.05 & 0.05 & 0.05 \\
Male 75+ & 0.01 & 0.00 & 0.02 & 0.03 \\
Female 18-35 & 0.10 & 0.19 & 0.15 & 0.11 \\
Female 35-45 & 0.20 & 0.10 & 0.10 & 0.11 \\
Female 45-64 & 0.12 & 0.16 & 0.15 & 0.16 \\
Female 65-74 & 0.05 & 0.05 & 0.07 & 0.06 \\
Female 75+ & 0.02 & 0.00 & 0.03 & 0.05 \\
second. Education & 0.49 & 0.57 & 0.63 & 0.64 \\
University degree & 0.16 & 0.22 & 0.18 & 0.18 \\
employed & 0.40 & 0.53 & 0.58 & 0.60 \\
self-employed & - & 0.09 & 0.10 & 0.10 \\
part-time & 0.12 & - & - & \\
housewife /-man & 0.36 & 0.18 & 0.08 & 0.06 \\
trainee & 0.02 & 0.08 & 0.02 & 0.01 \\
retired & 0.09 & 0.11 & 0.19 & 0.21 \\
unemployed & 0.00 & 0.01 & 0.02 & 0.01 \\
Lake Geneva & 0.16 & 0.17 & 0.18 & 0.19 \\
Espace Mittelland & 0.23 & 0.24 & 0.23 & 0.24 \\
North-West CH & 0.16 & 0.14 & 0.14 & 0.13 \\
Zurich & 0.14 & 0.17 & 0.17 & 0.18 \\
East CH & 0.17 & 0.14 & 0.14 & 0.13 \\
Central CH & 0.09 & 0.09 & 0.09 & 0.09 \\
Ticino & 0.05 & 0.04 & 0.05 & 0.05 \\
Suppl. Insurance & 0.50 & 0.53 & 0.39 & 0.31 \\
HMO & & & 0.04 & 0.06 \\
Deductible 150/230) & & & 0.54 & 0.31 \\
Deductible 300/400 & & & 0.31 & 0.25 \\
Deductible 600 & & & 0.01 & 0.16 \\
Deductible 1200 & & 0.08 & 0.05 \\
Deductible 1500 & & 0.02 & 0.17 \\
& & & &
\end{tabular}


Table 2: Quintile distributions, inequality and inequity indices

All visits (standardized distribution)

\begin{tabular}{|c|c|c|c|c|c|c|c|c|}
\hline & \multicolumn{4}{|c|}{ quintile distribution } & \multirow[b]{2}{*}{ Richest } & \multirow[b]{2}{*}{ Total } & \multirow[b]{2}{*}{$\mathbf{C M}$} & \multirow[b]{2}{*}{ HI } \\
\hline & Poorest & 2 & 3 & 4 & & & & \\
\hline \multicolumn{9}{|c|}{ All visits } \\
\hline 1982 & 4.647 & 4.820 & 4.926 & 4.143 & 4.601 & 4.627 & -0.048 & -0.014 \\
\hline 1992 & 3.364 & 3.300 & 3.380 & 3.362 & 3.175 & 3.316 & -0.032 & -0.005 \\
\hline 1997 & 3.816 & 4.224 & 3.824 & 3.802 & 3.836 & 3.900 & -0.053 & -0.011 \\
\hline 2002 & 3.629 & 3.479 & 3.507 & 3.490 & 3.457 & 3.512 & -0.044 & -0.006 \\
\hline \multicolumn{9}{|c|}{ Prob visit } \\
\hline 1982 & 0.721 & 0.711 & 0.771 & 0.756 & 0.771 & 0.746 & 0.012 & $\mathbf{0 . 0 1 7}$ \\
\hline 1992 & 0.731 & 0.752 & 0.745 & 0.763 & 0.777 & 0.754 & 0.004 & 0.012 \\
\hline 1997 & 0.692 & 0.717 & 0.714 & 0.716 & 0.719 & 0.712 & -0.006 & 0.007 \\
\hline 2002 & 0.742 & 0.749 & 0.758 & 0.760 & 0.751 & 0.752 & -0.005 & 0.003 \\
\hline \multicolumn{9}{|c|}{ Cond. Visit } \\
\hline 1982 & 6.253 & 6.698 & 6.335 & 5.444 & 5.988 & 6.137 & -0.060 & -0.025 \\
\hline 1992 & 4.526 & 4.422 & 4.532 & 4.383 & 4.148 & 4.401 & -0.036 & -0.013 \\
\hline 1997 & 5.312 & 5.769 & 5.225 & 5.245 & 5.290 & 5.369 & -0.047 & -0.012 \\
\hline 2002 & 4.719 & 4.489 & 4.479 & 4.484 & 4.456 & 4.525 & -0.039 & -0.008 \\
\hline
\end{tabular}

GP visits (standardized distribution)

\begin{tabular}{|c|c|c|c|c|c|c|c|c|}
\hline & \multicolumn{5}{|c|}{ quintile distribution } & \multirow[b]{2}{*}{ Total } & \multirow[b]{2}{*}{ CM } & \multirow[b]{2}{*}{ HI } \\
\hline & Poorest & 2 & 3 & 4 & Richest & & & \\
\hline \multicolumn{9}{|c|}{ All visits } \\
\hline 1982 & 3.300 & 3.517 & 3.436 & 2.804 & 3.068 & 3.225 & -0.063 & -0.027 \\
\hline 1997 & 2.760 & 2.738 & 2.431 & 2.471 & 2.320 & 2.544 & -0.084 & -0.040 \\
\hline 2002 & 2.369 & 2.348 & 2.324 & 2.342 & 2.139 & 2.304 & -0.062 & -0.018 \\
\hline \multicolumn{9}{|c|}{ Prob visit } \\
\hline 1982 & 0.643 & 0.650 & 0.671 & 0.632 & 0.621 & 0.644 & -0.008 & -0.006 \\
\hline 1997 & 0.617 & 0.640 & 0.617 & 0.620 & 0.620 & 0.623 & -0.018 & -0.001 \\
\hline 2002 & 0.560 & 0.584 & 0.587 & 0.590 & 0.580 & 0.580 & -0.005 & 0.008 \\
\hline \multicolumn{9}{|c|}{ Cond. Visit } \\
\hline 1982 & 5.059 & 5.393 & 5.114 & 4.418 & 4.925 & 4.986 & -0.055 & -0.020 \\
\hline 1997 & 4.268 & 4.179 & 3.813 & 3.882 & 3.660 & 3.967 & -0.066 & -0.035 \\
\hline 2002 & 4.123 & 3.866 & 3.839 & 3.858 & 3.549 & 3.849 & $-\mathbf{0 . 0 5 7}$ & -0.029 \\
\hline
\end{tabular}


Table 2 continued: Quintile distributions, inequality and inequity indices

Specialist visits (standardized distribution)

\begin{tabular}{|c|c|c|c|c|c|c|c|c|}
\hline & \multicolumn{8}{|c|}{ quintile distribution } \\
\hline & Poorest & 2 & 3 & 4 & Richest & Total & $\mathbf{C M}$ & HI \\
\hline \multicolumn{9}{|c|}{ All visits } \\
\hline 1982 & 1.370 & 1.335 & 1.521 & 1.382 & 1.573 & 1.436 & -0.014 & 0.022 \\
\hline 1992 & & & & & & & & \\
\hline 1997 & 1.175 & 1.575 & 1.484 & 1.406 & 1.581 & 1.444 & -0.002 & 0.034 \\
\hline 2002 & 1.258 & 1.464 & 1.504 & 1.561 & 1.774 & 1.512 & 0.051 & 0.071 \\
\hline \multicolumn{9}{|c|}{ Prob visit } \\
\hline 1982 & 0.336 & 0.344 & 0.391 & 0.406 & 0.462 & 0.388 & 0.041 & 0.065 \\
\hline 1992 & & & & & & & & \\
\hline 1997 & 0.368 & 0.445 & 0.435 & 0.472 & 0.473 & 0.439 & 0.018 & 0.045 \\
\hline 2002 & 0.397 & 0.434 & 0.437 & 0.498 & 0.491 & 0.451 & 0.034 & 0.048 \\
\hline \multicolumn{9}{|c|}{ Cond. Visit } \\
\hline 1982 & 3.805 & 3.660 & 3.795 & 3.363 & 3.385 & 3.590 & -0.055 & -0.032 \\
\hline 1992 & & & & & & & & \\
\hline 1997 & 3.055 & 3.278 & 3.282 & 3.077 & 3.571 & 3.254 & -0.019 & -0.009 \\
\hline 2002 & 3.113 & 3.438 & 3.296 & 2.973 & 3.295 & 3.224 & $\mathbf{0 . 0 1 7}$ & 0.024 \\
\hline
\end{tabular}

Number of hospital nights (standardized distribution)

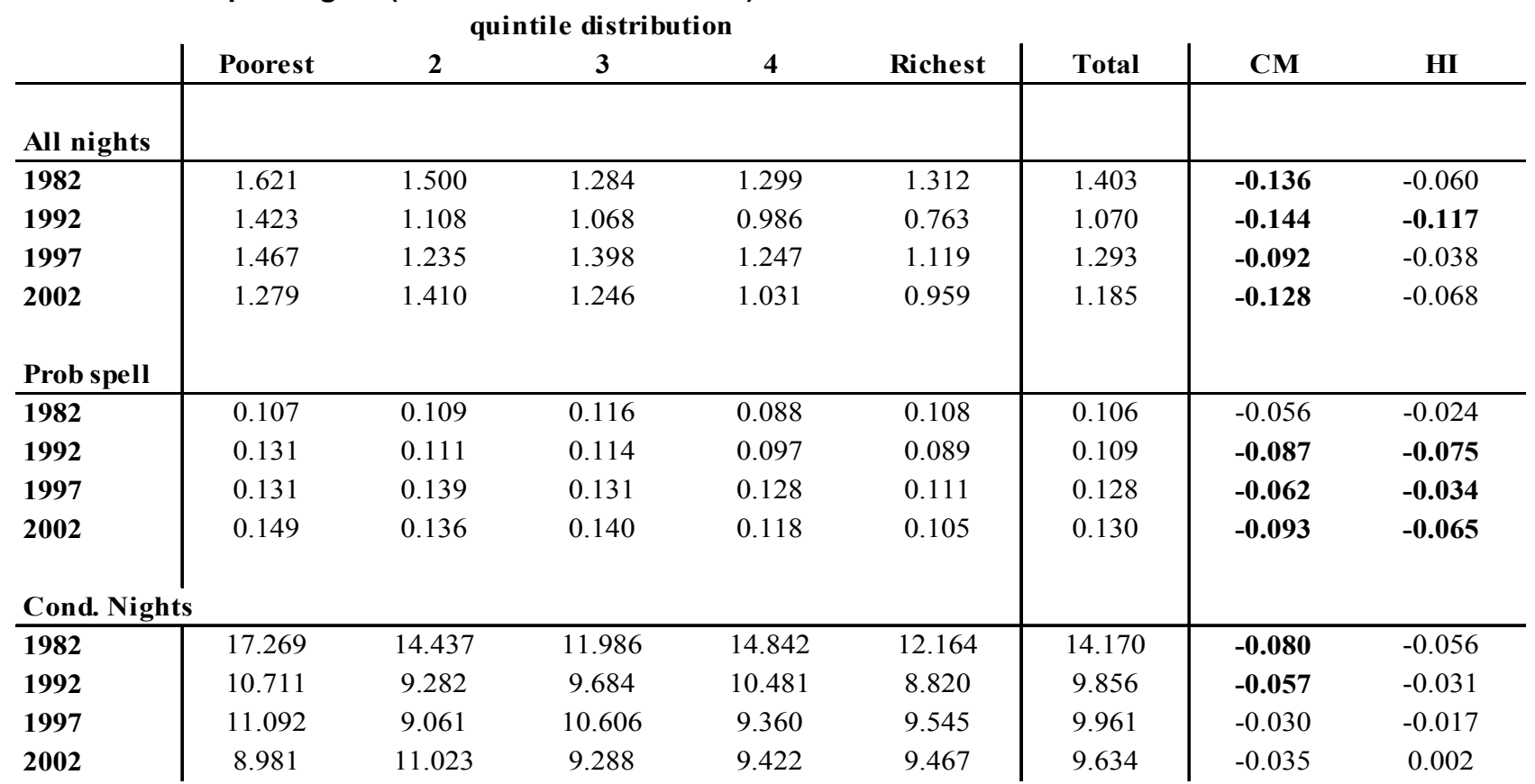


Table 3: Decomposition analysis of specialist visits 2002

\begin{tabular}{|c|c|c|c|c|c|}
\hline & Mean & $\mathrm{Cl}$ & & Contrib & Sum \\
\hline $\mathrm{HI}$ & & & & 0.071 & 0.071 \\
\hline Ininc & 7.955 & 0.035 & 0.305 & 0.058 & 0.058 \\
\hline SAH good & 0.623 & 0.007 & 0.168 & 0.000 & \\
\hline SAH average & 0.109 & -0.125 & 0.790 & -0.007 & \\
\hline SAH poor & 0.031 & -0.280 & 1.223 & -0.007 & \\
\hline SAH very poor & 0.004 & -0.170 & 1.856 & -0.001 & -0.015 \\
\hline ADL hamp. & 0.168 & -0.084 & 1.212 & -0.012 & \\
\hline chron. Condition & 0.249 & -0.030 & 0.971 & -0.005 & -0.017 \\
\hline Male 35-45 & 0.122 & 0.030 & -0.133 & 0.000 & \\
\hline Male 45-64 & 0.179 & 0.045 & -0.127 & -0.001 & \\
\hline Male 65-74 & 0.054 & -0.078 & -0.230 & 0.001 & \\
\hline Male $75+$ & 0.031 & -0.116 & -0.658 & 0.002 & 0.001 \\
\hline Female 18-35 & 0.114 & 0.046 & 2.006 & 0.007 & \\
\hline Female 35-45 & 0.110 & -0.055 & 1.063 & -0.004 & \\
\hline Female 45-64 & 0.160 & 0.037 & 0.502 & 0.002 & \\
\hline Female 65-74 & 0.063 & -0.164 & 0.051 & 0.000 & \\
\hline Female $75+$ & 0.046 & -0.197 & -0.561 & 0.003 & 0.008 \\
\hline second. Education & 0.644 & 0.007 & 0.425 & 0.001 & \\
\hline University degree & 0.181 & 0.308 & 0.663 & 0.026 & 0.027 \\
\hline retired & 0.213 & -0.144 & -0.028 & 0.001 & \\
\hline self-employed & 0.101 & -0.019 & -0.175 & 0.000 & \\
\hline apprentice/student & 0.009 & -0.242 & -0.235 & 0.000 & \\
\hline unemployed & 0.012 & -0.167 & -0.487 & 0.001 & \\
\hline inactive & 0.007 & -0.283 & 2.258 & -0.003 & \\
\hline housewive/-man & 0.063 & -0.157 & 0.327 & -0.002 & -0.004 \\
\hline Espace Mittelland & 0.242 & -0.054 & -0.172 & 0.002 & \\
\hline North-West CH & 0.134 & 0.064 & -0.381 & -0.002 & \\
\hline Zurich & 0.175 & 0.150 & -0.373 & -0.007 & \\
\hline East CH & 0.129 & -0.091 & -0.453 & 0.004 & \\
\hline Central CH & 0.086 & -0.036 & -0.413 & 0.001 & \\
\hline Ticino & 0.048 & -0.159 & -0.468 & 0.002 & 0.000 \\
\hline Suppl. Insurance & 0.314 & 0.242 & 0.169 & 0.009 & 0.009 \\
\hline $\mathrm{HMO}$ & 0.062 & 0.098 & -0.169 & -0.001 & \\
\hline Deductible $400 \mathrm{CHF}$ & 0.245 & -0.057 & -0.123 & 0.001 & \\
\hline Deductible $600 \mathrm{CHF}$ & 0.157 & 0.077 & -0.199 & -0.002 & \\
\hline Deductible $1200 \mathrm{CHF}$ & 0.052 & 0.158 & -0.542 & -0.003 & \\
\hline Deductible $1500 \mathrm{CHF}$ & 0.172 & 0.155 & -0.410 & -0.008 & -0.012 \\
\hline
\end{tabular}


Figure 1a: All visits

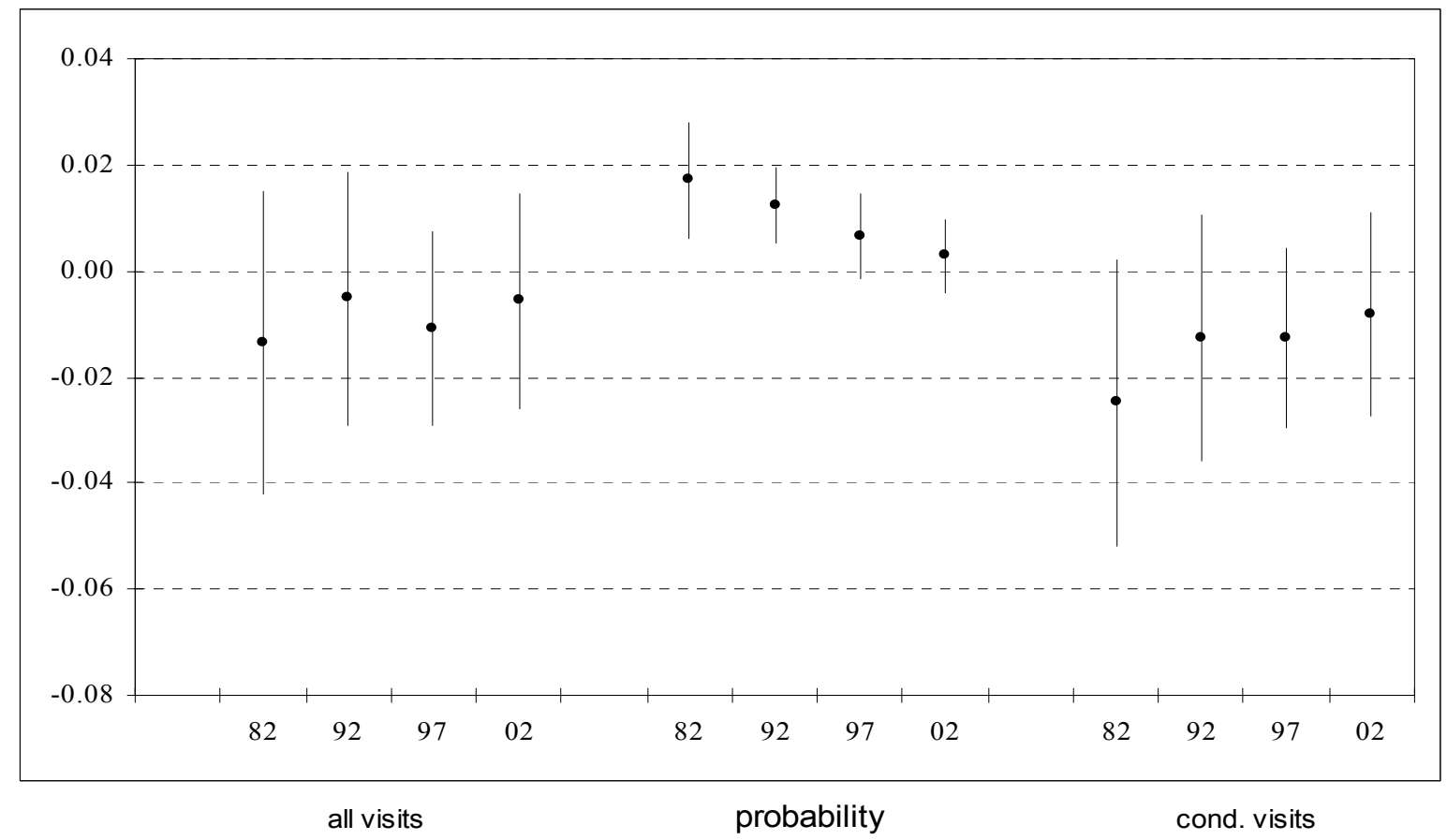

Figure 1b: GP Visits

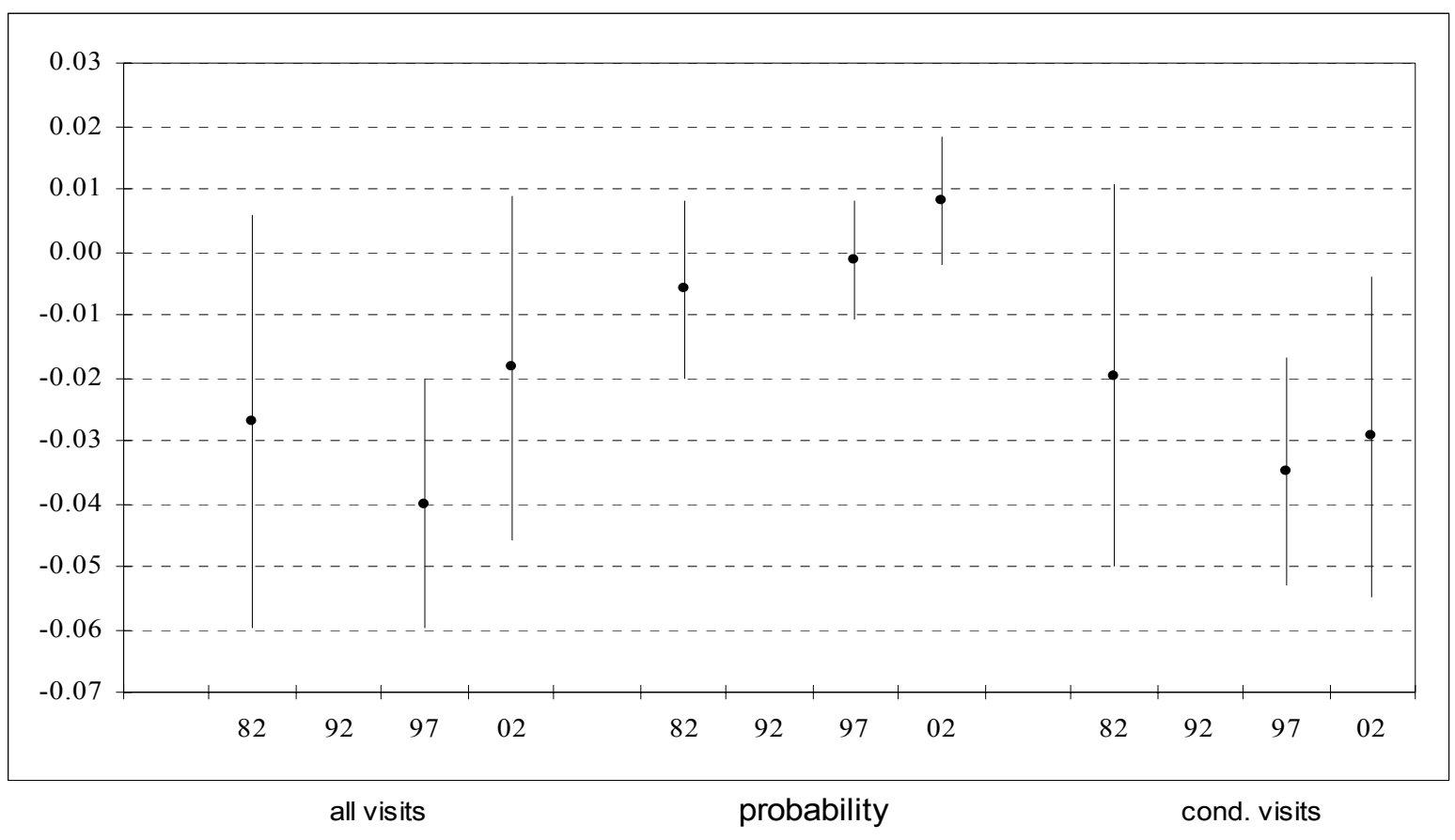


Figure 1c: Specialist Visits

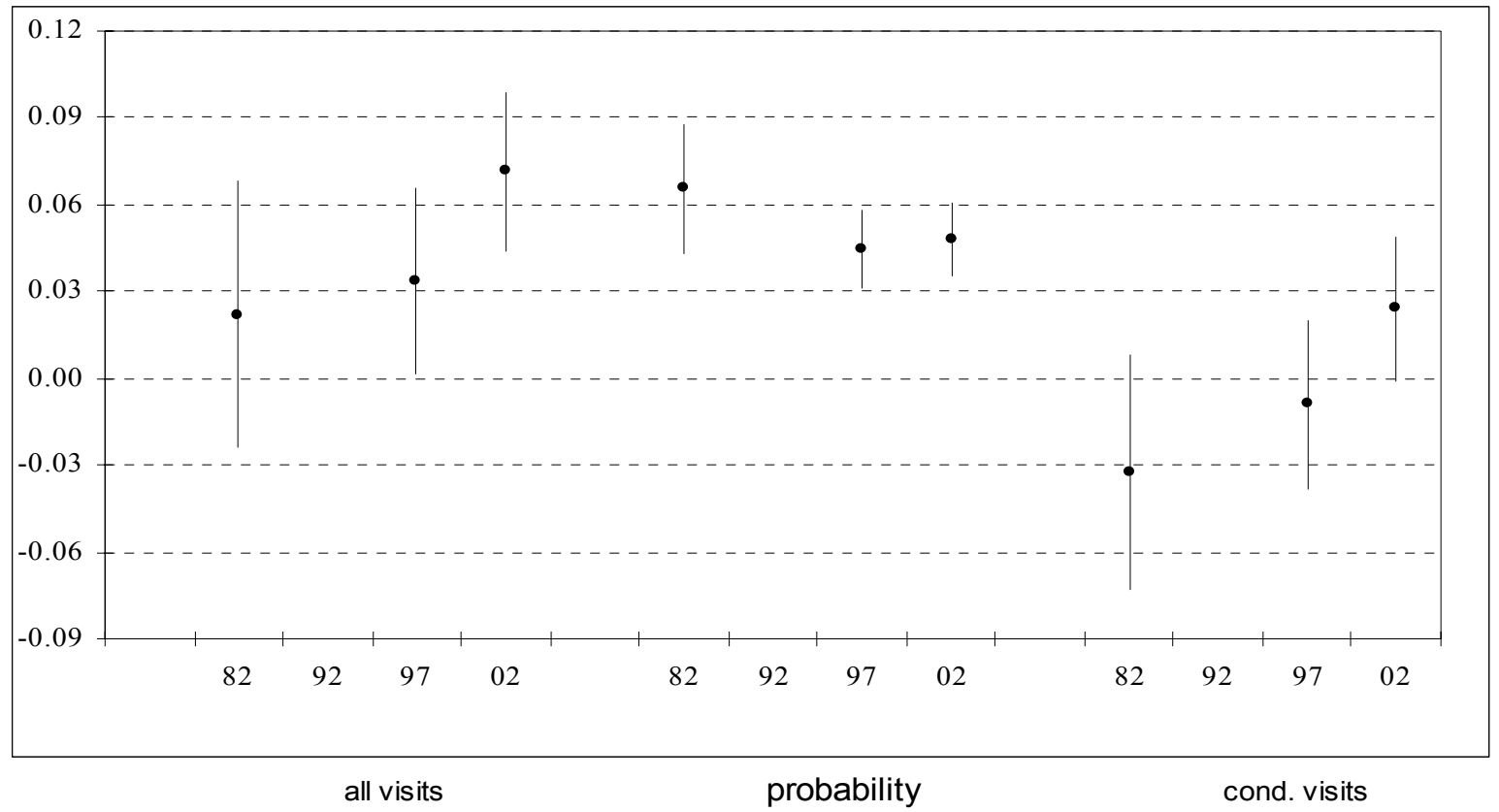

Figure 1d: Hospital Nights

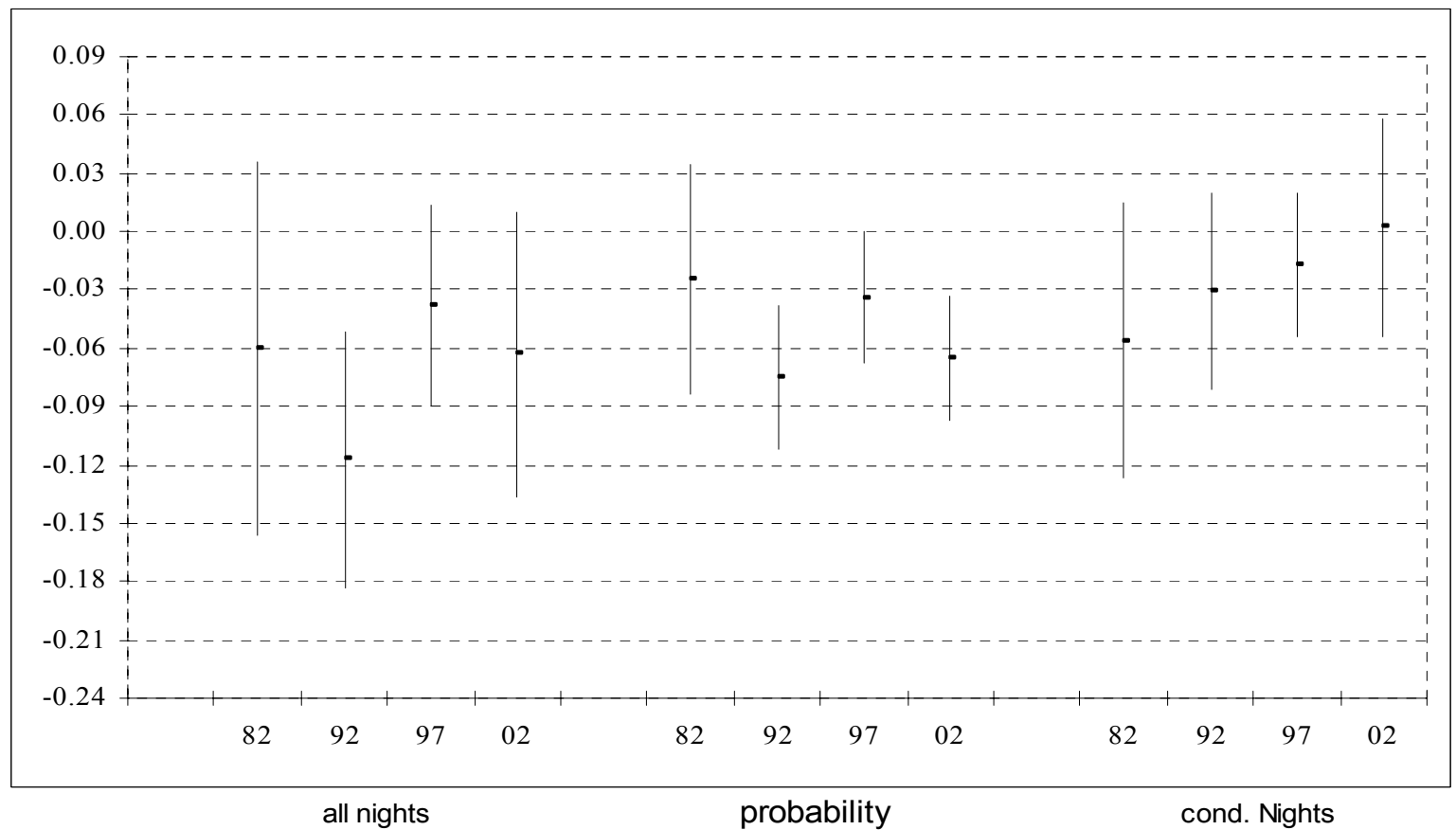



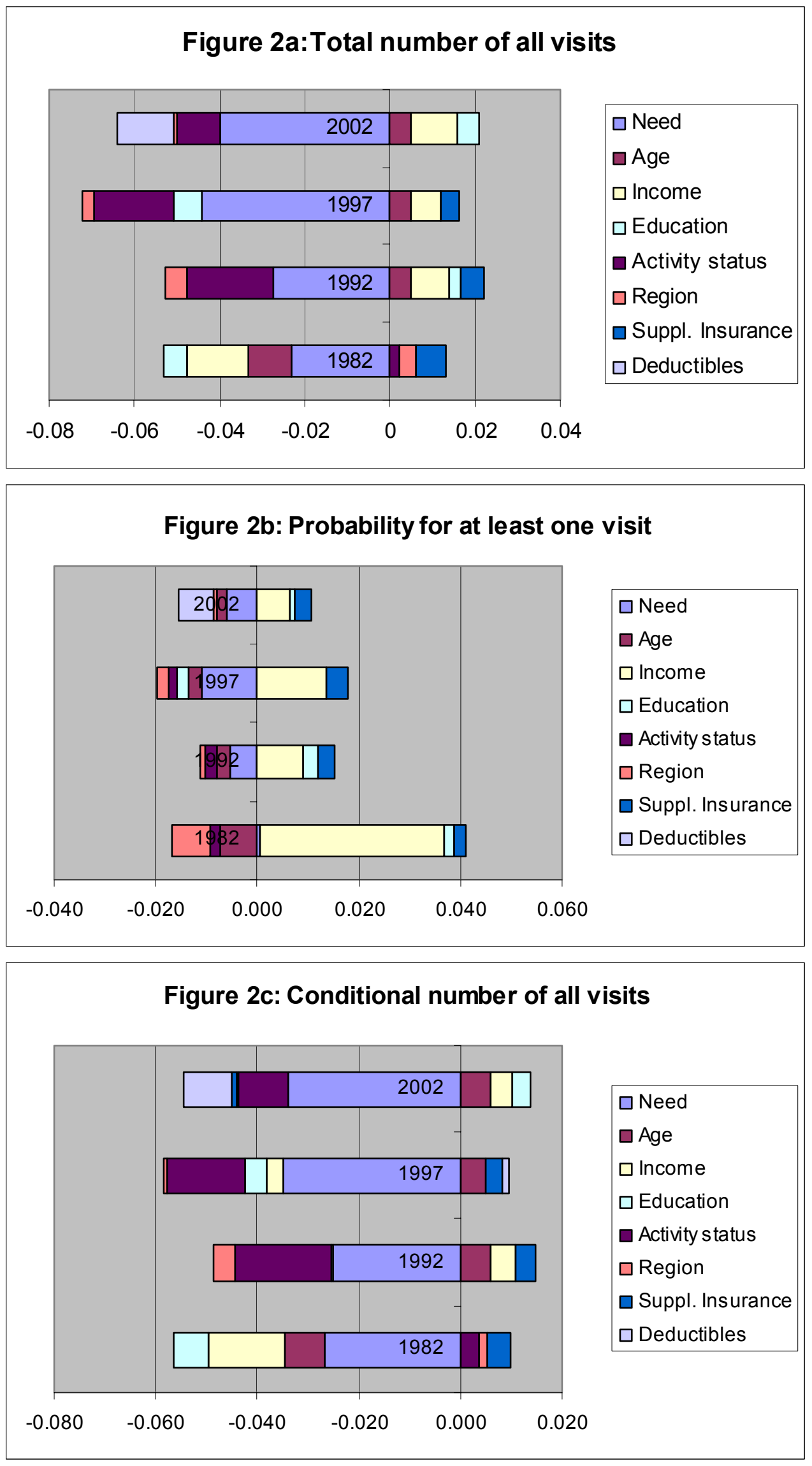


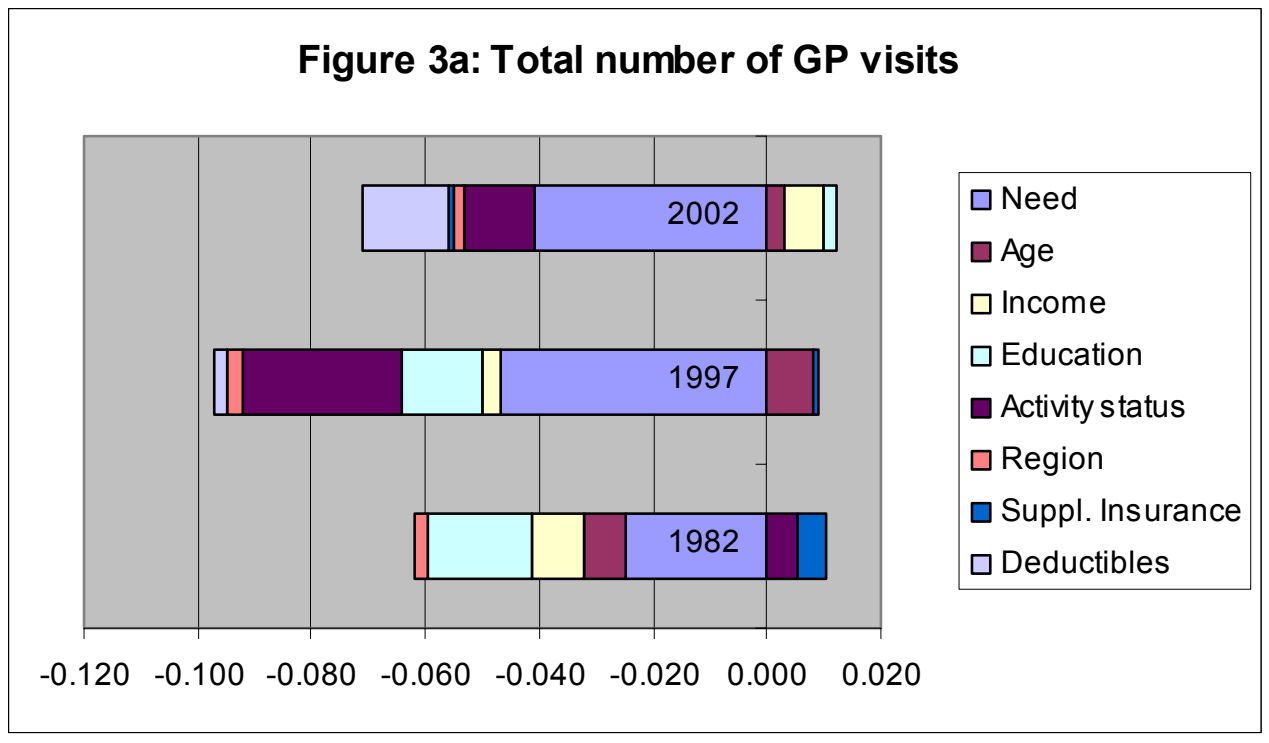

Figure 3b: Probability for at least one GP visit

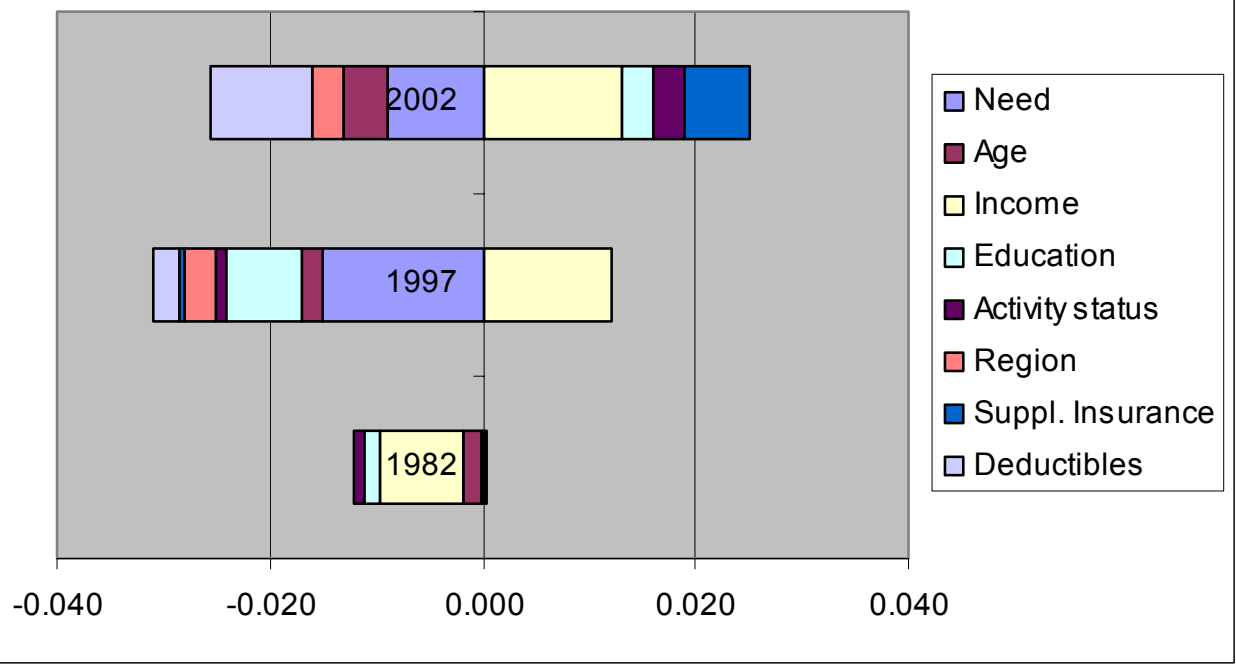

Figure 3c: Conditional number of GP visits

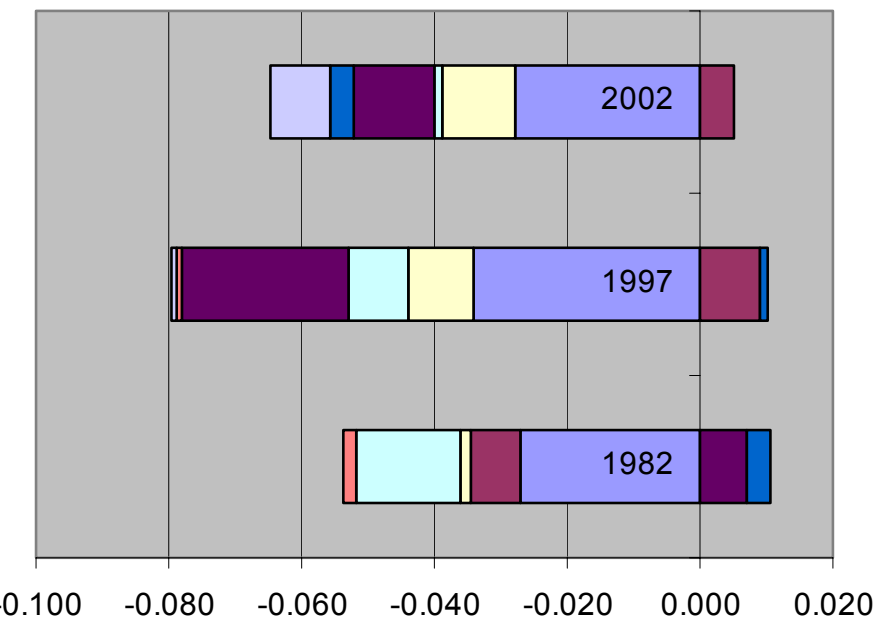

\begin{tabular}{|l|}
$\square$ Need \\
$\square$ Age \\
$\square$ Income \\
$\square$ Education \\
$\square$ Activity status \\
$\square$ Region \\
$\square$ Suppl. Insurance \\
$\square$ Deductibles
\end{tabular}




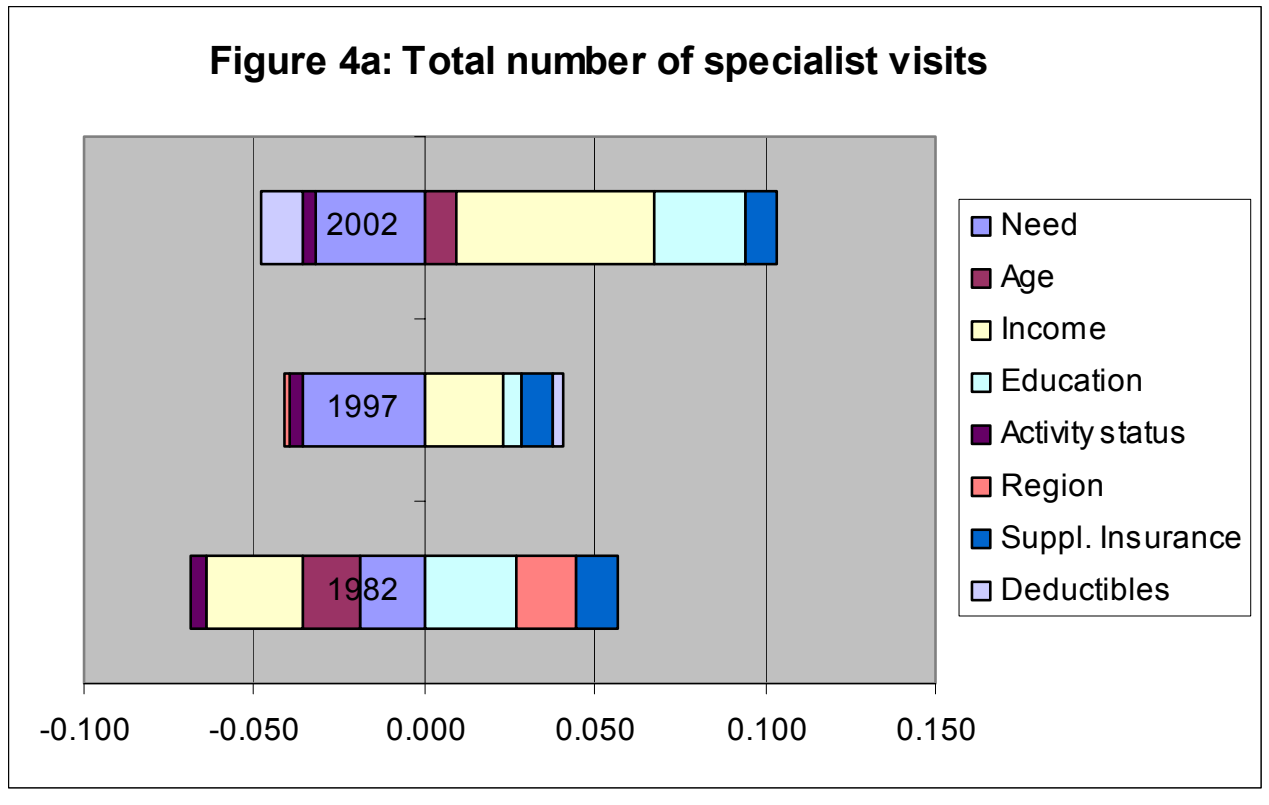

Figure 4b: Probability for at least one specialist visit

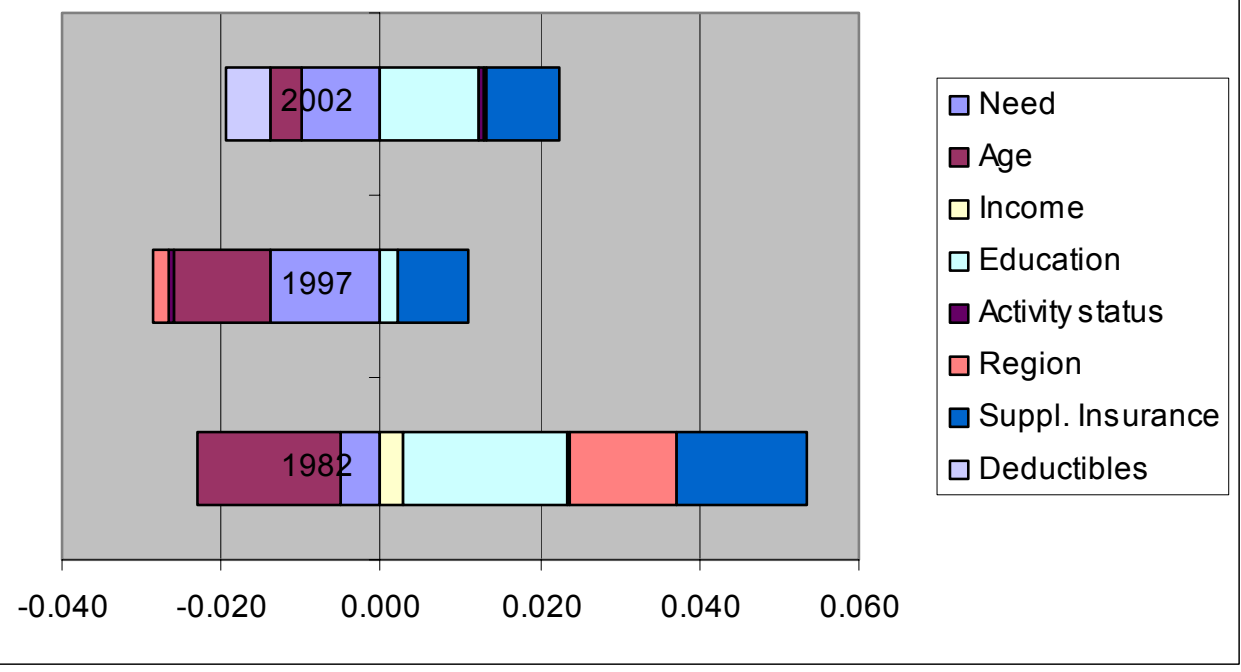

Figure 4c: Conditional number of specialist visits

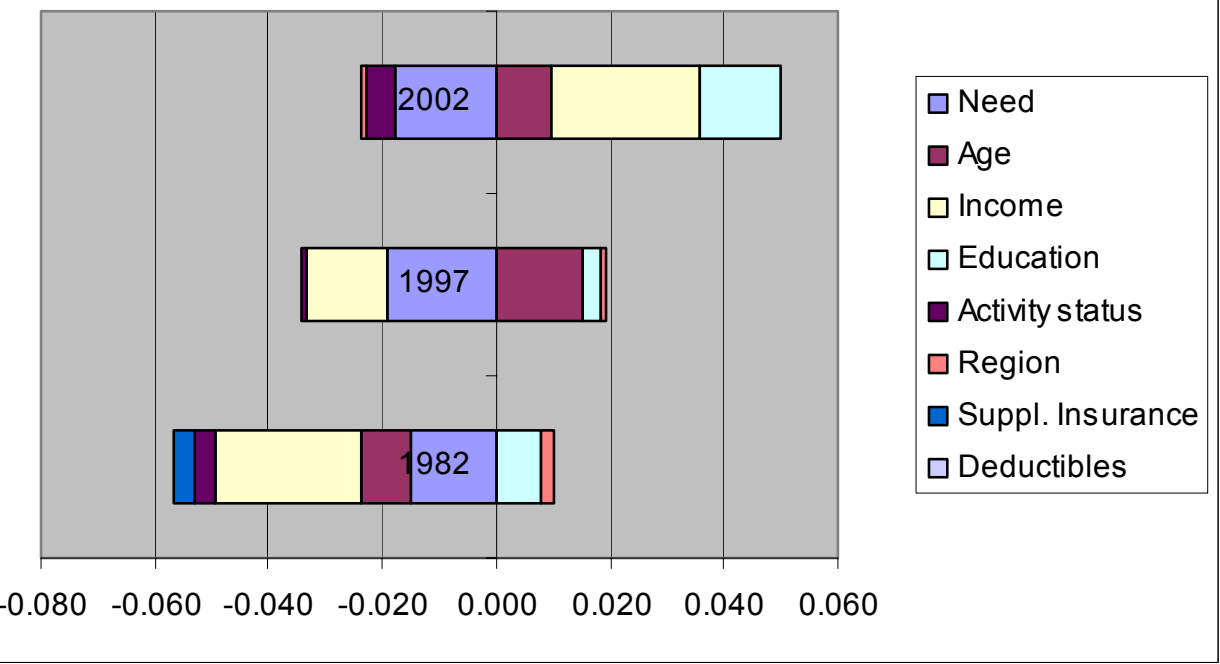


Figure 5a: Total number of hospital nights

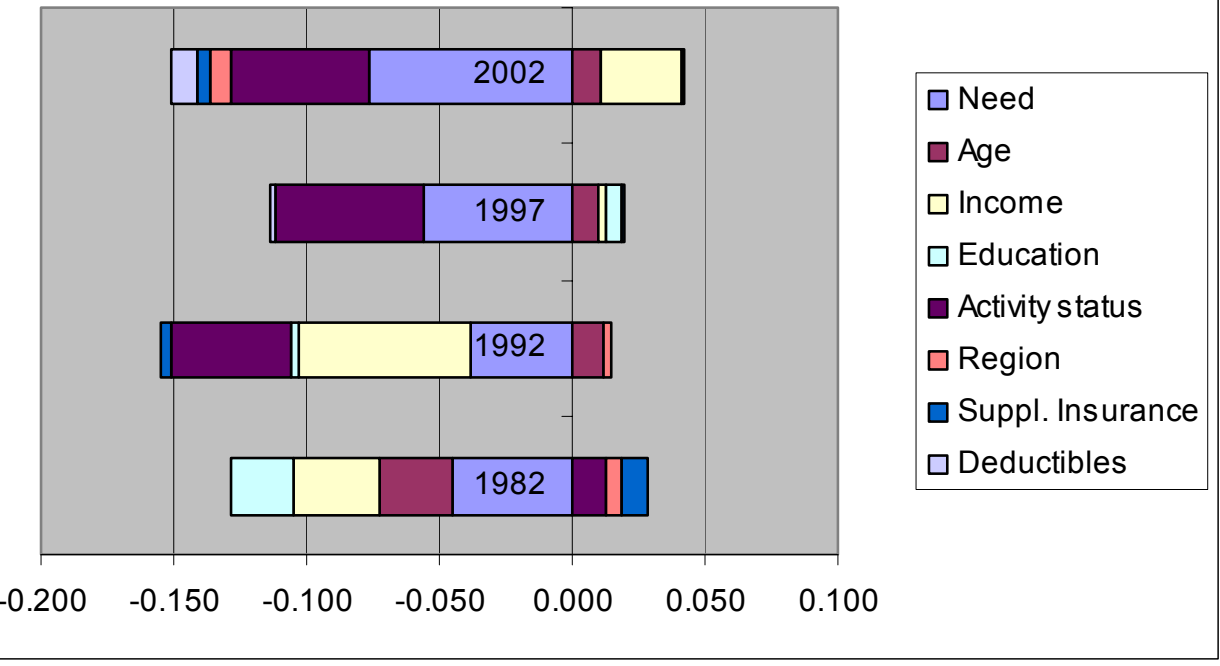

Figure 5b: Probability for a hospital stay

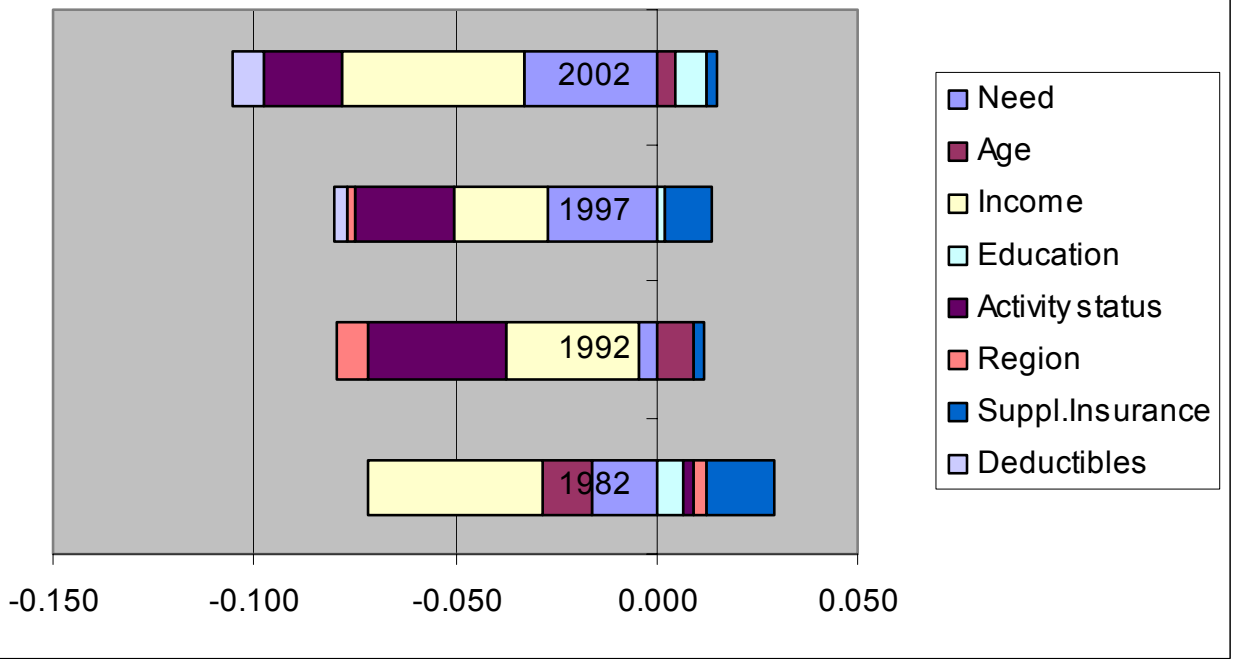

Figure 5c: Conditional number of hospital nights

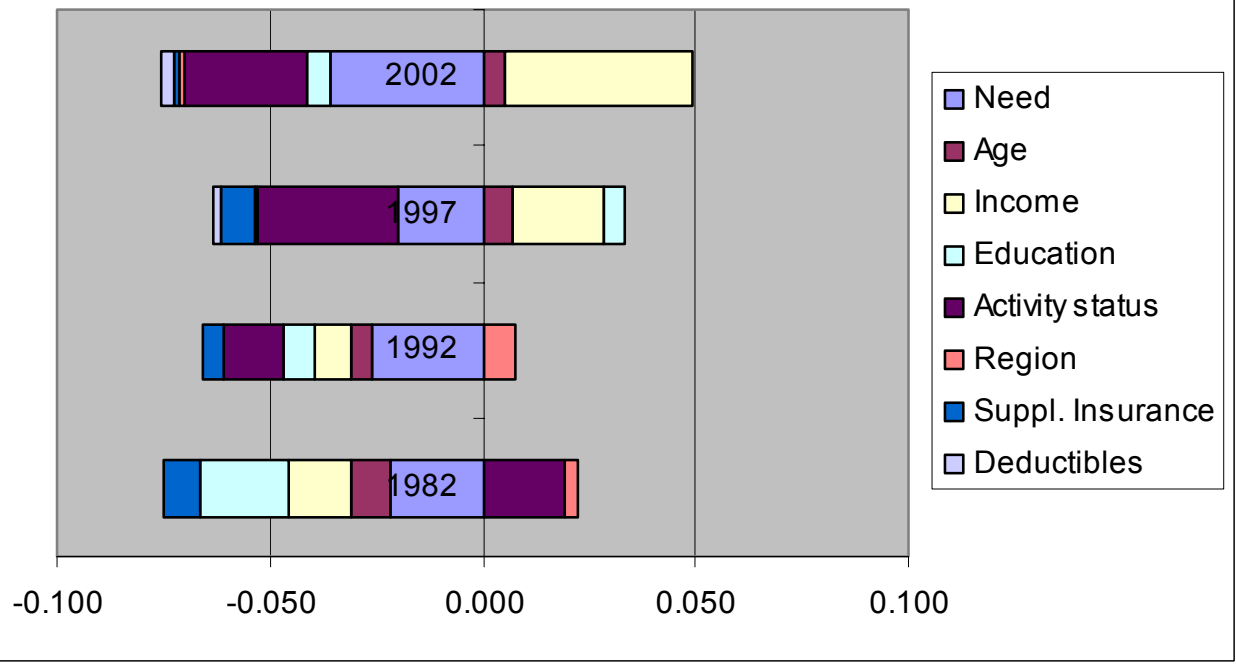

